\title{
Effects of Inspiratory Muscle Training and Calisthenics-and-Breathing Exercises in COPD With and Without Respiratory Muscle Weakness
}

\author{
Renata P Basso-Vanelli PT PhD, Valéria A Pires Di Lorenzo PT PhD, \\ Ivana G Labadessa PT MSc, Eloisa M G Regueiro PT PhD, Mauricio Jamami PT PhD, \\ Evelim LFD Gomes PT PhD, and Dirceu Costa PT PhD
}

\begin{abstract}
BACKGROUND: Patients with COPD may experience respiratory muscle weakness. Two therapeutic approaches to the respiratory muscles are inspiratory muscle training and calisthenics-andbreathing exercises. The aims of the study are to compare the effects of inspiratory muscle training and calisthenics-and-breathing exercises associated with physical training in subjects with COPD as an additional benefit of strength and endurance of the inspiratory muscles, thoracoabdominal mobility, physical exercise capacity, and reduction in dyspnea on exertion. In addition, these gains were compared between subjects with and without respiratory muscle weakness. METHODS: 25 subjects completed the study: 13 composed the inspiratory muscle training group, and 12 composed the calisthenics-and-breathing exercises group. Subjects were assessed before and after training by spirometry, measurements of respiratory muscle strength and test of inspiratory muscle endurance, thoracoabdominal excursion measurements, and the 6-min walk test. Moreover, scores for the Modified Medical Research Council dyspnea scale were reported. RESULTS: After intervention, there was a significant improvement in both groups of respiratory muscle strength and endurance, thoracoabdominal mobility, and walking distance in the 6-min walk test. Additionally, there was a decrease of dyspnea in the 6-min walk test peak. A difference was found between groups, with higher values of respiratory muscle strength and thoracoabdominal mobility and lower values of dyspnea in the 6-min walk test peak and the Modified Medical Research Council dyspnea scale in the inspiratory muscle training group. In the inspiratory muscle training group, subjects with respiratory muscle weakness had greater gains in inspiratory muscle strength and endurance. CONCLUSIONS: Both interventions increased exercise capacity and decreased dyspnea during physical effort. However, inspiratory muscle training was more effective in increasing inspiratory muscle strength and endurance, which could result in a decreased sensation of dyspnea. In addition, subjects with respiratory muscle weakness that performed inspiratory muscle training had higher gains in inspiratory muscle strength and endurance but not of dyspnea and submaximal exercise capacity. (ClinicalTrials.gov registration NCT01510041.) Key words: COPD; respiratory muscles; breathing exercises; dyspnea; physical therapy. [Respir Care 2016;61(1):50-60. () 2016 Daedalus Enterprises]
\end{abstract}

\section{Introduction}

COPD, characterized by not fully reversible air flow obstruction, ${ }^{1}$ causes impairment of respiratory and periph- eral muscles, leading to a decreased capacity for exercise. ${ }^{2,3}$ According to Singer et al, ${ }^{4}$ by compromising either respiratory or lower limb muscles independently, exercise capacity in subjects with COPD may be reduced. That emphasizes the importance of training both respiratory and

Centro Universitário Claretiano, Batatais, São Paulo, Brazil. Dr Gomes is affiliated with the Universidade Nove de Julho-UNINOVE, São Paulo, SP, Brazil. Dr Costa is affiliated with the Universidade Federal de São Carlos (UFSCar), São Carlos, São Paulo and Universidade Nove de Julho-UNINOVE, São Paulo, SP, Brazil. 
peripheral muscles in pulmonary rehabilitation programs to maximize the effects of exercise training in general.

Respiratory muscles in patients with COPD experience reduction in strength and/or endurance, leading to muscle dysfunction. ${ }^{5}$ This occurs due to changes in the rib cage geometry caused by lung hyperinflation, which alters the length-tension curve of the diaphragm muscle. It also occurs due to systemic factors and structural changes in those muscles, ${ }^{6,7}$ since strength mainly depends on muscle mass, and endurance is related to muscle fiber aerobic properties. ${ }^{5}$

In the literature, the forms of therapeutic approach to respiratory muscles are inspiratory muscle training, ${ }^{8}$ which uses overload for such training, and calisthenics-andbreathing exercises, which are characterized by breathing exercises and stretching of respiratory muscles and/or by exercises involving the trunk and upper limbs to improve mobility of the rib cage muscles. ${ }^{9-12}$

As for inspiratory muscle training, a meta-analysis ${ }^{8}$ showed that it is an effective type of training for subjects with COPD, for increasing the strength and endurance of inspiratory muscles, reducing dyspnea, and improving functional capacity. The authors further suggest that those who would benefit most are those with inspiratory muscle weakness. However, additional effects of inspiratory muscle training on general physical exercise on the functional capacity of subjects with COPD are not well defined. ${ }^{13}$

Calisthenics-and-breathing exercises, in turn, are able to readjust the length-tension ratio of the respiratory muscles, increase thoracoabdominal mobility, reduce the sensation of dyspnea, and increase the capacity for exercise. ${ }^{9-12}$ However, despite being frequently employed in clinical practice, scientific evidence of these benefits is scarce, because there is a lack of reports in the literature about such an approach.

Minaguchi et $\mathrm{al}^{10}$ compared the effects of inspiratory muscle training and calisthenics-and-breathing exercises separately and noticed that both were able to increase submaximal exercise capacity, but due to different mechanisms. Given this finding, questions regarding the differences in results between inspiratory muscle training and calisthenics-and-breathing exercises still prevail, especially

This work was supported by scholarships from the Coordenação de Aperfeiçoamento de Pessoal de nível Superior (CAPES). The authors have disclosed no conflicts of interest.

Dr Regueiro presented a version of this paper at the European Respiratory Society Annual Congress 2013, held September 7-13, 2013, in Barcelona, Spain.

Correspondence: Renata P Basso-Vanelli PT PhD, Rodovia Washington Luiz, Km 235, Laboratório de Espirometria e Fisioterapia Respiratória (DFisio), CEP: 13565-905, São Carlos, SP, Brasil. E-mail: renata.fisio@gmail.com.

DOI: $10.4187 /$ respcare. 03947

\section{QUICK LOOK}

\section{Current knowledge}

COPD is characterized by irreversible airflow obstruction that causes impairment of the respiratory and skeletal muscles, leading to decreased exercise capacity. Training both respiratory and peripheral muscles in pulmonary rehabilitation programs is encouraged to maximize the positive effects of exercise training.

\section{What this paper contributes to our knowledge}

In a small group of COPD subjects, both inspiratory muscle training and callisthenic exercises increased exercise capacity and decreased dyspnea during physical effort. Inspiratory muscle training was more effective in improving inspiratory muscle strength and endurance. In subjects with respiratory muscle weakness, inspiratory muscle training resulted in greater gains in inspiratory muscle strength and endurance but not in dyspnea or submaximal exercise capacity.

when associated with physical training, characterized by aerobic training. Also, there are many questions about the existence of differences in the effects of these interventions between patients with and without respiratory muscle weakness. Such problems led to the hypothesis that inspiratory muscle training could provide increased inspiratory muscle strength and endurance, whereas calisthenics-and-breathing exercises could increase thoracoabdominal mobility. However, both approaches would lead to clinical improvement through a decrease in dyspnea and an increase in exercise capacity. In addition, those subjects with respiratory muscle weakness would have more significant gains.

Hence, the main objectives of this study were to compare the effects of inspiratory muscle training and calisthenics-and-breathing exercises associated with physical training in subjects with COPD, as an additional benefit of strength and endurance of the inspiratory muscles, thoracoabdominal mobility, physical exercise capacity, and dyspnea on exertion. A secondary objective was to compare those gains between COPD subjects with and without respiratory muscle weakness in each intervention.

\section{Methods}

\section{Subjects}

This is a prospective randomized study conducted at the Health School Institute and at the Respiratory Physiotherapy Special Institute at the Universidade Federal de São 
Carlos. Subjects with COPD referred to those institutes were evaluated, treated, and divided into 2 treatment groups according to a randomizing plan generated by a computer program. ${ }^{14}$ All subjects provided written consent. The study was approved by the Ethics and Research Committee (Report 141/2010).

Subjects were of both sexes, $>50$ y old, and had a clinical diagnosis of moderate to very severe COPD determined by spirometry before and after bronchodilator, classified according to the Global Initiative for Chronic Obstructive Lung Disease (GOLD). ${ }^{1}$ They were also clinically stable, with no history of infection or exacerbation of respiratory symptoms for at least 1 month before the beginning of data collection. Subjects had not participated in or attended a pulmonary rehabilitation program for at least 6 months.

Those with other respiratory, cardiovascular, and musculoskeletal diseases or with neurological or orthopedic sequel that would make it impossible to perform the tests were excluded. Those who were taking $\beta$ blockers and/or undergoing prolonged oxygen therapy were also excluded.

\section{Experimental Protocol}

All subjects underwent an initial history taking. Before and after the training period, they underwent the following tests, performed by the same evaluator: spirometry, measurement of respiratory muscle strength, endurance test of inspiratory muscles, thoracoabdominal excursion measurements, 6-min walk test, and exercise treadmill test. The Modified Medical Research Council dyspnea scale (MMRC) was also applied.

Spirometry was performed by using a portable spirometer (Easy One, ndd Medical, Zurich, Switzerland), according to the standards of the American Thoracic Society/European Respiratory Society, ${ }^{15}$ with the subject sitting and wearing a nose clip. The values obtained were compared with those expected according to Pereira et al. ${ }^{16}$

The assessment of respiratory muscle strength consisted of measurements of maximal inspiratory pressure from residual volume and of measurements of maximum expiratory pressure, starting from total lung capacity, with the subject seated and wearing a nose clip, according to Black and Hyatt, ${ }^{17}$ with an analog manovacuometer graduated in $\mathrm{cm} \mathrm{H}_{2} \mathrm{O}$ (Ger-Ar, São Paulo, Brazil). It was carried out for a maximum of 5 maneuvers, of which at least 3 were reproducible, and the highest value was chosen for analysis. The obtained values were compared with those predicted by Neder et al. ${ }^{18}$

The assessment of inspiratory muscle endurance was performed by using PowerBreathe (Gaiam, Southam, United Kingdom), coupled to an analog manovacuometer (Ger-Ar, São Paulo, Brazil). The latter was used to control the stipulated load that was being generated and to give feedback to the subject during the test. The assessment was performed with the subject seated and wearing a nose clip. That evaluation consisted of 2 tests, an incremental test and a constant one, performed on the same day with an interval of $30 \mathrm{~min}$ between them, and the methods described in the literature were adapted for this study. ${ }^{19-21}$

The incremental test started with $10 \mathrm{~cm} \mathrm{H}_{2} \mathrm{O}$ (minimum load of the device), held for $2 \mathrm{~min}$, followed by $1 \mathrm{~min}$ of rest. After that, the load was increased by $10 \mathrm{~cm} \mathrm{H}_{2} \mathrm{O}$, and so on. The heaviest load that could be sustained for at least 1 min was considered the value of sustained maximum inspiratory pressure.

The constant test was performed at $80 \%$ of sustained maximum inspiratory pressure, with the time limit run of $30 \mathrm{~min}$ in this study. Such a protocol has already been described in a study by Dias et al. ${ }^{22}$

For both tests, a breathing pattern was not fixed, but the respiratory rate was constantly monitored and recorded. ${ }^{21}$ The tests were considered finished when the subject could not generate the determined load in 3 successive attempts or spontaneously, due to dyspnea and/or fatigue. Verbal encouragement was given to stimulate maximum performance.

Thoracoabdominal excursion measurements were performed by a measuring tape, scaled in $\mathrm{cm}$, placed horizontally into 3 levels: axillary, xiphoidian, and abdominal (at the umbilicus level). The subject was in an orthostatic position, with the upper body relaxed and with a bare chest. For each of these levels, the subject was instructed to perform a maximal inspiration followed by a maximal expiration, without directing the air to any specific region. This was repeated 3 times. The highest value of difference between inspiration and expiration was used to analysis. ${ }^{23}$

The 6-min walk test was performed on a 30-m-long, 1.5 -m-wide track in accordance with the standards of the American Thoracic Society. ${ }^{24}$ Two tests were performed on the same day with an interval of $30 \mathrm{~min}$, and the longest walked distance was computed. $\mathrm{S}_{\mathrm{pO}_{2}}$, heart rate, and blood pressure were monitored. In addition, the sensations of dyspnea and fatigue of the lower limbs were assessed by the Borg CR 10 scale.

An exercise treadmill test was performed in accordance with the American Thoracic Society/American College of Chest Physicians, ${ }^{25}$ by using the modified Bruce protocol. ${ }^{26}$ It was a limited symptom test, whose objectives were to determine the intensity of the aerobic training and the existence of cardiovascular comorbidities that would prevent the performance of physical training. A validated version of the MMRC was used, a scale that determines the degree of dyspnea; the greater the score, the worse the limit of the subject. ${ }^{27}$ 


\section{Physical Training Program}

The subjects were divided into 2 groups. Both groups underwent physical training, but one of them also performed inspiratory muscle training (the inspiratory muscle training group); the other, together with physical training, performed calisthenics-and-breathing exercises (the calisthenics-and-breathing exercises group).

The whole training regime was carried out for 4 months, 3 times a week on alternate days, for a total of 48 sessions. It consisted of stretching of the upper and lower limbs and treadmill exercise started at $80 \%$ of the speed and inclination obtained in the exercise treadmill test. ${ }^{28}$ The training intensity was adjusted over the weeks by using the sensation of dyspnea as a parameter, keeping it between 4 and 6 on the Borg CR 10 scale, ${ }^{29}$ and always keeping the heart rate at $85 \%$ of maximum. Oxygen was supplemented during exercise, when the $\mathrm{S}_{\mathrm{pO}_{2}}$ was below $88 \%$. The initial time was $20 \mathrm{~min}$, progressing to $30 \mathrm{~min}$. Lower limb (flexor and extensor group) resistance exercises were performed with free weights, with increases of $1-2 \mathrm{~kg}$ every 2 weeks according to subject tolerance. ${ }^{30,31}$

In the inspiratory muscle training group, the training of the inspiratory muscles was carried out by PowerBreathe. The subject inspired and expired in the equipment for 2 min and rested for $1 \mathrm{~min}$. This was repeated 7 times, and the total training time was $21 \mathrm{~min}$. It began with $10 \mathrm{~cm} \mathrm{H}_{2} \mathrm{O}$ (minimum load of the device) in the first week for all subjects, and it was increased in $10-\mathrm{cm}_{2} \mathrm{O}$ increments until $60 \%$ of the initial maximum inspiratory pressure at the end of the first month. After the first month, the load was adjusted every 2 weeks for the updated $60 \%$ of maximum inspiratory pressure, for the period of 4 months. The breathing pattern was kept free. This protocol is an adaptation of the protocols of Hill et $\mathrm{al}^{21}$ and Beckerman et al. ${ }^{32}$

The calisthenics-and-breathing exercises group performed a program of specific exercises aimed at improving biomechanics and chest mobility, adapted from the program described by Probst et al. ${ }^{11}$ The sequence of exercises was designed so that the complexity progressively increased every month. A series of 9 exercises, each one performed 15 times, was carried out (Table 1).

\section{Statistical Analysis}

In order to investigate the distribution of data, we employed the Shapiro-Wilk test. Descriptive statistics were performed to characterize the sample, and the data were expressed as mean $\pm \mathrm{SD}$ and median (interquartile range) for variables with parametric and nonparametric distribution, respectively. The absolute difference $(\Delta=$ post pre) was calculated for all variables, and for this difference, we assessed the difference between subjects with and without respiratory muscle weakness. The cutoff value for respiratory muscle weakness was set as $\leq 60 \mathrm{~cm} \mathrm{H}_{2} \mathrm{O}$. For variables with parametric distribution, the paired Student $t$ test was used to analyze intragroup variance. The independent Student $t$ test was used to compare intergroup variance. For the nonparametric distributions, Mann-Whitney and Wilcoxon tests were used. Two-way analysis of variance with Tukey's post hoc test was used for the comparisons between subjects with and without respiratory muscle weakness, within and between groups. The statistical program used was SPSS for Windows 17.0 (SPSS, Chicago, Illinois). The level of significance was 5\%. The effect size was calculated by using Cohen's d, and the results were interpreted based on Cohen, ${ }^{33}$ as follows: small (0.21-0.49), medium (0.50-0.79), or large $(\geq 0.80)$.

The sample size was calculated according to a pilot study based on the absolute value of respiratory muscle strength (maximum inspiratory pressure $=88.6 \pm 17.5 \mathrm{l}$ $66.6 \pm 12.1$ ) and endurance (sustained maximum inspiratory pressure $=83.3 \pm 12.1 / 46.6 \pm 23.3)$ and dyspnea $($ MMRC $=0.8 \pm 0.4 / 1.3 \pm 0.5)$ variables, which revealed that to achieve $80 \%$ power with a significance level of $5 \%$, the sample for each group should be 12 subjects with COPD. The program used was Ene 2.0.

\section{Results}

There were 54 eligible subjects with COPD, of which 25 were excluded for not meeting the established criteria. The 29 enrolled subjects were assessed and randomized: 16 composed the inspiratory muscle training group, and 13 composed the calisthenics-and-breathing exercises group. There was a sample loss of 4 subjects; thus, 13 subjects in the inspiratory muscle training group and 12 in calisthenics-and-breathing exercises group completed the study, constituting the final sample with 25 subjects (Fig. 1). All of the subjects were on continuous use of long-acting bronchodilators and inhaled corticosteroids, and there was no change in medication during the intervention period.

The characteristics of each group are presented in Table 2, with no difference between groups in the pre-intervention variables. According to the new GOLD classification, there were 2 subjects classified at $\mathrm{A}$ grade, 3 at B, 3 at C, and 5 at $\mathrm{D}$ in the inspiratory muscle training group and 1 subject at A, 2 at B, 4 at $\mathrm{C}$, and 5 at $\mathrm{D}$ in the calisthenicsand-breathing exercises group. After the intervention, the points in the MMRC scale decreased in the inspiratory muscle training group, with a significant difference between groups.

Table 3 shows that after intervention, there was significant increase in maximum inspiratory pressure, percentof-predicted maximum inspiratory pressure, and sustained maximum inspiratory pressure in both groups, with a greater increase in the inspiratory muscle training group. For these variables, the improvement averaged $26 \mathrm{~cm} \mathrm{H}_{2} \mathrm{O}$ in max- 
Table 1. Monthly Calisthenics-and-Breathing Program

\begin{tabular}{|c|c|c|c|}
\hline 1st Month & 2nd Month & 3rd Month & 4th Month \\
\hline $\begin{array}{l}\text { Orientation about } \\
\text { respiratory patterns } \\
\text { and pursed lip } \\
\text { breathing. }\end{array}$ & $\begin{array}{l}\text { Abdominal exercise: In DD } \\
\text { horizontally, with LL } \\
\text { flexed and resting on the } \\
\text { floor, flex the upper } \\
\text { torso, with UL behind } \\
\text { the head. }\end{array}$ & $\begin{array}{l}\text { Abdominal exercise: In DD } \\
\text { horizontally, with LL } \\
\text { flexed and supported, } \\
\text { flex upper torso with UL } \\
\text { behind the head. }\end{array}$ & $\begin{array}{l}\text { Abdominal exercise: In DD } \\
\text { horizontally, with LL } \\
\text { flexed and resting on the } \\
\text { floor, flex upper torso } \\
\text { with UL crossed in front } \\
\text { of the torso. }\end{array}$ \\
\hline $\begin{array}{l}\text { Abdominal exercise with } \\
\text { elevated DD. }\end{array}$ & $\begin{array}{l}\text { Abdominal exercise: In } \\
\text { DD, drop LL to one side } \\
\text { and then to the other } \\
\text { side. }\end{array}$ & $\begin{array}{l}\text { Abdominal exercise: In DD } \\
\text { horizontally, with LL } \\
\text { flexed and supported, } \\
\text { drop LL to one side and } \\
\text { then to the other side. }\end{array}$ & $\begin{array}{l}\text { Abdominal exercise: In DD } \\
\text { horizontally, with LL } \\
\text { flexed and resting on a } \\
\text { chair, flex upper torso } \\
\text { with UL crossed in front } \\
\text { of the torso. }\end{array}$ \\
\hline Bridge exercise. & $\begin{array}{l}\text { Abdominal exercise: In } \\
\text { horizontal DD with LL } \\
\text { flexed and resting on the } \\
\text { floor, extend and raise } \\
\text { one LL at a time. }\end{array}$ & $\begin{array}{l}\text { Abdominal exercise: In DD } \\
\text { horizontally, with LL } \\
\text { flexed and supported, } \\
\text { extend a LL associated } \\
\text { with UL contralateral } \\
\text { elevation. }\end{array}$ & $\begin{array}{l}\text { Sitting on a chair, lift a LL } \\
\text { and then the other, } \\
\text { holding a bat at the } \\
\text { shoulder line. }\end{array}$ \\
\hline $\begin{array}{l}\text { In elevated DD with } \\
\text { flexed and supported } \\
\text { LL, flex chin. }\end{array}$ & $\begin{array}{l}\text { Sitting on a chair, holding } \\
\text { bat with extended UL at } \\
\text { the shoulder line, } \\
\text { perform torso rotation. }\end{array}$ & $\begin{array}{l}\text { Sitting on a chair, push one } \\
\text { hand against the other at } \\
\text { the midline and perform } \\
\text { torso rotation. }\end{array}$ & $\begin{array}{l}\text { Sitting on a chair, adduct } \\
\text { and abduct UL extended } \\
\text { at horizontal with } 1 \mathrm{~kg} \text {. }\end{array}$ \\
\hline $\begin{array}{l}\text { Sitting, raise RUL, } \\
\text { flexing the } \\
\text { contralateral torso. }\end{array}$ & $\begin{array}{l}\text { Sitting on a chair holding a } \\
\text { bat with extended UL at } \\
\text { the shoulder line, adduct } \\
\text { the scapula. }\end{array}$ & $\begin{array}{l}\text { Sitting on a chair holding a } \\
\text { bat with the UL } \\
\text { extended at the shoulder } \\
\text { line, rotate the torso. }\end{array}$ & $\begin{array}{l}\text { Sitting on a chair with } \\
\text { extended UL at the } \\
\text { shoulder line holding } 1 \\
\text { kg, flex and extend } \\
\text { elbows, adducting the } \\
\text { scapula. }\end{array}$ \\
\hline $\begin{array}{l}\text { Sitting on the chair, lift } \\
\text { to the UL with the bat } \\
\text { at shoulder line. }\end{array}$ & $\begin{array}{l}\text { Sitting on a chair, push one } \\
\text { hand against the other at } \\
\text { midline. }\end{array}$ & $\begin{array}{l}\text { Sitting on a chair, adduct } \\
\text { and abduct the UL at } \\
\text { horizontal in front of the } \\
\text { torso. }\end{array}$ & $\begin{array}{l}\text { Sitting with the bat behind } \\
\text { the head, perform torso } \\
\text { rotation. }\end{array}$ \\
\hline $\begin{array}{l}\text { Sitting on the chair to } \\
\text { take shoulders back, } \\
\text { adduct the scapula. }\end{array}$ & $\begin{array}{l}\text { Standing with the UL } \\
\text { crossed in front of the } \\
\text { torso, perform torso } \\
\text { rotation. }\end{array}$ & $\begin{array}{l}\text { Standing to hold the bat } \\
\text { behind the head, perform } \\
\text { torso rotation. }\end{array}$ & $\begin{array}{l}\text { Standing, keep the bat with } \\
\text { UL extended at the } \\
\text { shoulder line and abduct } \\
\text { LL, once on each side. }\end{array}$ \\
\hline $\begin{array}{l}\text { Standing, perform lateral } \\
\text { flexion of the torso } \\
\text { with the UL extended } \\
\text { to the side of the } \\
\text { torso. }\end{array}$ & $\begin{array}{l}\text { Standing with bat behind } \\
\text { the head, perform lateral } \\
\text { flexion of the torso. }\end{array}$ & $\begin{array}{l}\text { Standing to hold the bat } \\
\text { with UL extended at the } \\
\text { shoulder line, perform } \\
\text { torso rotation. }\end{array}$ & $\begin{array}{l}\text { Standing, hold the bat over } \\
\text { the head and lower and } \\
\text { raise the UL, holding the } \\
\text { bat behind the head. }\end{array}$ \\
\hline $\begin{array}{l}\text { Standing with LL } \\
\text { extended and abducted } \\
\text { to hold the bat behind } \\
\text { the head, perform } \\
\text { diaphragmatic } \\
\text { breathing. }\end{array}$ & $\begin{array}{l}\text { Standing, flex and extend } \\
\text { the UP at the shoulders; } \\
\text { holding a bat, adduct the } \\
\text { scapula. }\end{array}$ & $\begin{array}{l}\text { Standing, hold the bat with } \\
\text { UL extended at shoulder, } \\
\text { adduct the scapula. }\end{array}$ & $\begin{array}{l}\text { Standing, with crossed UP } \\
\text { in front of the torso, } \\
\text { perform lateral flexion of } \\
\text { torso. }\end{array}$ \\
\hline $\begin{array}{l}\mathrm{DD}=\text { dorsal decubitus } \\
\mathrm{LL}=\text { lower limbs } \\
\mathrm{UL}=\text { upper limbs } \\
\mathrm{RUL}=\text { right upper limb }\end{array}$ & & & \\
\hline
\end{tabular}

imum inspiratory pressure, $26 \%$ in percent-of-predicted maximum inspiratory pressure, and $19 \mathrm{~cm} \mathrm{H}_{2} \mathrm{O}$ in sustained maximum inspiratory pressure for the inspiratory muscle training group and $10 \mathrm{~cm} \mathrm{H}_{2} \mathrm{O}$ in maximum inspiratory pressure, $10.6 \%$ in percent-of-predicted maximum inspira- tory pressure, and $4 \mathrm{~cm} \mathrm{H}_{2} \mathrm{O}$ in sustained maximum inspiratory pressure for the calisthenics-and-breathing exercises group. The relation sustained maximum inspiratory pressure and maximum inspiratory pressure showed a significant decrease after intervention for the calisthenics- 


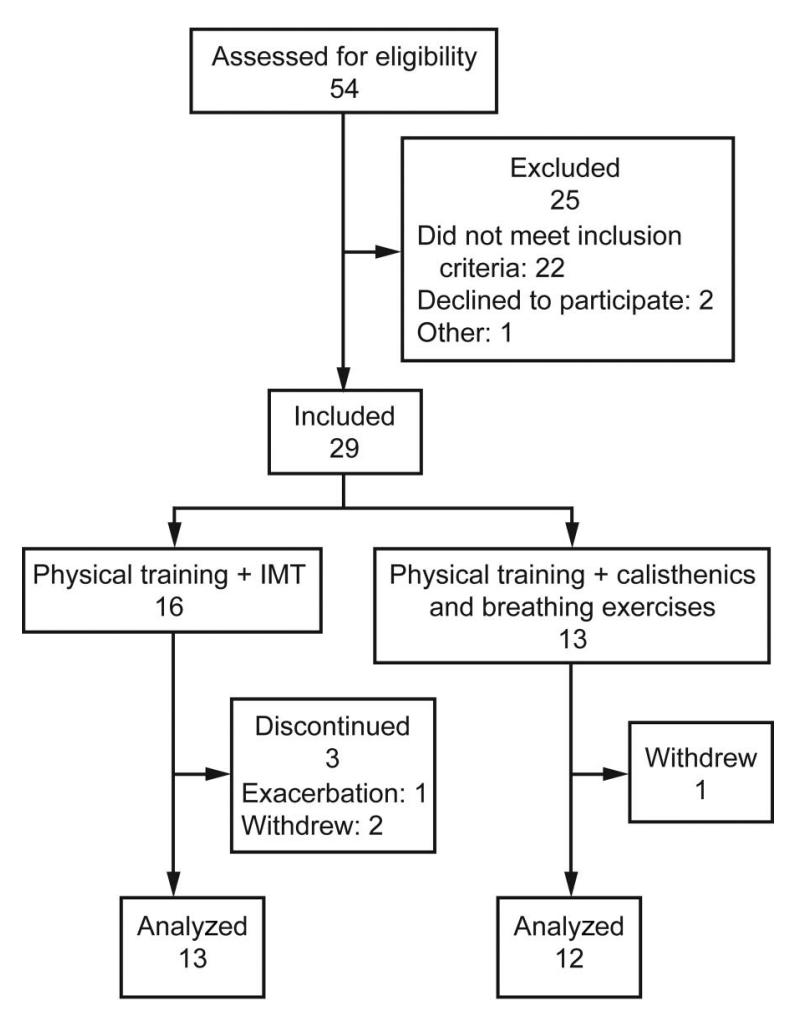

Fig. 1. Flow chart. IMT = inspiratory muscle training.

and-breathing exercises group, with a significant difference between the groups. Regarding the time limit, there was no difference between groups; however, it increased significantly in the inspiratory muscle training group after the intervention, with an average rise of $468 \mathrm{~s}$. The sizes of the effects on maximum inspiratory pressure, sustained maximum inspiratory pressure, and time limit were greater in the inspiratory muscle training group when compared with the calisthenics-and-breathing exercises group (Table 3).

There was a significant increase of both axillary and abdominal mobility in the inspiratory muscle training group and an increase of the 3 levels in the calisthenics-andbreathing exercises group. A significant difference between the groups was noticed only in the values of abdominal mobility. However, the effect size for this variable was higher in both groups.

It was noticed that the 6-min walk distance increased significantly after intervention in both groups, with an average gain of $46 \mathrm{~m}$ in the inspiratory muscle training group and $34 \mathrm{~m}$ in the calisthenics-and-breathing exercises group, with no significant difference between groups. The effect size was medium for this variable in the inspiratory muscle training group and small in the calisthenics-andbreathing exercises group (Table 3 ).

For dyspnea, there was a significant decrease in postintervention tests of inspiratory muscle endurance only in the inspiratory muscle training group, with no difference between groups. For the 6-min walk test, there was a sig- nificant decrease in dyspnea in both groups. It was greater in the inspiratory muscle training group, and only for this group, there was a decrease in the fatigue of the lower limbs. The effect size for these variables was large (Table 3 ).

Regarding the analysis between subjects with and without respiratory muscle weakness in each group, it was noted that in the inspiratory muscle training group, those subjects with muscle weakness showed significantly greater gains in maximum inspiratory pressure and sustained maximum inspiratory pressure. However, dyspnea, seen according to the MMRC scale, decreased significantly in subjects without respiratory muscle weakness. In the calisthenics-and-breathing exercises group, there was no difference in gains after intervention between subjects with and without respiratory muscle weakness (Table 4).

Comparing each one of the interventions, it may be noticed that in the inspiratory muscle training group, both subjects with and without respiratory muscle weakness had a greater rise in strength and respiratory muscle endurance, compared with the calisthenics-and-breathing exercises group. However, in MMRC, subjects with respiratory muscle weakness in the calisthenics-and-breathing exercises group had a significant decrease in dyspnea compared with the inspiratory muscle training group, and subjects without respiratory muscle weakness in the inspiratory muscle training group had a significant decrease compared with the calisthenics-and-breathing exercises group (Table 4).

\section{Discussion}

It can be seen that in both groups, there was an increase of the strength and endurance of the inspiratory muscles as well as thoracoabdominal mobility and exercise capacity, characterized by the increase of 6-min walk distance and decrease of dyspnea in the 6-min walk test. However, the initial hypothesis that the specificity of the training was instrumental in the changes was confirmed, since there were higher strength and endurance gains of the inspiratory muscles in the inspiratory muscle training group when compared with the results of the calisthenics-and-breathing exercises group. This result is considered important because only in the inspiratory muscle training group we could see increases considered clinically relevant, according to the meta-analysis by Gosselink et al, ${ }^{8}$ in which the considered increase was $13 \mathrm{~cm} \mathrm{H}_{2} \mathrm{O}$ for maximum inspiratory pressure and sustained maximum inspiratory pressure and $261 \mathrm{~s}$ for time limit.

With regard to the definition of respiratory muscle weakness, there is no consensus in the scientific literature concerning the best cutoff. However, a cutoff of $\leq 60 \mathrm{~cm} \mathrm{H}_{2} \mathrm{O}$ was chosen because it is referenced for COPD. ${ }^{8}$

It was observed that those subjects with respiratory muscle weakness had greater strength and endurance improve- 
Table 2. Demographic, Anthropometric, and Spirometric Values, Dyspnea Level, and Oxygen Saturation Before and After Intervention of Both Groups

\begin{tabular}{|c|c|c|c|c|c|c|}
\hline & \multicolumn{3}{|c|}{ IMT Group $(n=13)$} & \multicolumn{3}{|c|}{$\begin{array}{l}\text { Calisthenics-and-Breathing Exercises Group } \\
\qquad(n=12)\end{array}$} \\
\hline & Before & After & $P$ & Before & After & $P$ \\
\hline \multicolumn{7}{|l|}{ Sex, $n$} \\
\hline Male & 11 & & & 9 & & \\
\hline Female & 2 & & & 3 & & \\
\hline Ex-smokers/current smokers & $11 / 2$ & & & $11 / 1$ & & \\
\hline Age, y & $67 \pm 12.8$ & & & $66 \pm 7.6$ & & \\
\hline Weight, kg & $62 \pm 10.4$ & $62 \pm 9.9$ & .87 & $57 \pm 9.8$ & $59.5 \pm 9.5$ & .82 \\
\hline Height, cm & $166 \pm 7.7$ & $165 \pm 7.5$ & .43 & $159 \pm 11.1$ & $159 \pm 10.1$ & .35 \\
\hline BMI, $\mathrm{kg} / \mathrm{m}^{2}$ & $23 \pm 3.9$ & $23 \pm 3.7$ & .83 & $23 \pm 3.1$ & $23 \pm 2.5$ & .63 \\
\hline $\mathrm{FEV}_{1} / \mathrm{FVC}$ & $50 \pm 11.7$ & $51 \pm 11.7$ & .56 & $42 \pm 11.2$ & $41 \pm 11$ & .20 \\
\hline \multicolumn{7}{|l|}{$\mathrm{FEV}_{1} / \mathrm{FVC}, \%$ predicted } \\
\hline $\mathrm{FEV}_{1}, \mathrm{~L}$ & $1.2 \pm 0.5$ & $1.3 \pm 0.5$ & .37 & $0.8 \pm 0.3$ & $0.8 \pm 0.2$ & .57 \\
\hline $\mathrm{FEV}_{1}, \%$ predicted & $47 \pm 18.5$ & $53 \pm 20$ & .28 & $36 \pm 9.7$ & $38 \pm 10$ & .40 \\
\hline FVC, L & $2.4 \pm 0.8$ & $2.5 \pm 0.7$ & .55 & $1.9 \pm 0.6$ & $2.0 \pm 0.6$ & .11 \\
\hline $\mathrm{FVC}, \%$ predicted & $75 \pm 23.1$ & $80 \pm 18.3$ & .69 & $66 \pm 8.8$ & $73 \pm 12.5$ & .44 \\
\hline SVC, L & $2.4 \pm 0.8$ & $2.5 \pm 0.7$ & .60 & $1.8 \pm 0.7$ & $2.0 \pm 0.7$ & .12 \\
\hline $\mathrm{SVC}, \%$ predicted & $72 \pm 21$ & $81 \pm 16.6$ & .20 & $66 \pm 13.8$ & $73 \pm 12$ & .16 \\
\hline $\mathrm{MVV}, \mathrm{L} / \mathrm{min}$ & $57.2 \pm 29.3$ & $60 \pm 25.9$ & .79 & $38.2 \pm 23.1$ & $37 \pm 15.6$ & .63 \\
\hline MVV, $\%$ predicted & $49 \pm 24.9$ & $51 \pm 22.6$ & .94 & $37 \pm 10.8$ & $40 \pm 14.1$ & .34 \\
\hline GOLD score & $3(2-3.5)$ & $2(2-3)$ & .08 & $3(3-3)$ & $3(2-3)$ & .65 \\
\hline MMRC score & $2(1-2)$ & $1(1-1)^{* \dagger}$ & .03 & $1.5(1-2)^{*}$ & $1(1-2)$ & .63 \\
\hline $\mathrm{S}_{\mathrm{pO}_{2}}, \%$ & $94 \pm 1.2$ & $94 \pm 1.1$ & .29 & $93 \pm 2.6$ & $94 \pm 2.0$ & .36 \\
\hline $\begin{array}{l}\text { Data are expressed as mean } \pm \mathrm{SD} \text { or } \mathrm{n} \\
\text { IMT Group = physical training associa } \\
\text { Calisthenics-and-Breathing Exercises } \mathrm{G} \\
\mathrm{BMI}=\text { body mass index } \\
\mathrm{SVC}=\text { slow vital capacity } \\
\mathrm{MVV}=\text { maximum voluntary ventilatio } \\
\text { GOLD = Global Initiative for Chronic } \\
\text { MMRC = Modified Medical Research } \\
* \text { Mann-Whitney test, } P<.05 \text { (between } \\
\dagger \text { Wilcoxon test, } P<.05 \text { (within-group }\end{array}$ & $\begin{array}{l}\text { quartile range). } \\
\text { iratory muscle trai } \\
\text { ical training associ } \\
\text { Lung Disease } \\
\text { nnea scale } \\
\text { ysis). }\end{array}$ & listhenics-and-bre & ises. & & & \\
\hline
\end{tabular}

ment when the inspiratory muscle training was performed. It is important to emphasize that the strength gains were not clinically significant, unlike the increases in endurance. In addition, dyspnea decreased more in those subjects without muscle weakness. However, those who were underwent calisthenics-and-breathing exercises were not different from those with or without muscle weakness.

Increases in inspiratory muscle strength and endurance may reflect not only an adaptation of neuromuscular characteristics, with greater recruitment of motor units, but also structural changes in the respiratory muscles. RamirezSarmiento et al, ${ }^{19}$ after conducting 5 weeks of the inspiratory muscle training at $40-50 \%$ of maximum inspiratory pressure, noticed an increase in fiber types I and II in the external intercostal muscle. In our study, the training occurred at $60 \%$ of maximum inspiratory pressure; therefore, structural changes in the respiratory muscles may have occurred as well. Also, despite the relatively high load, the inspiratory muscle training was well tolerated by our subjects.

As for the endurance test, it was noticed that only sustained maximum inspiratory pressure was significantly different between the groups, which corroborates the results of Hill et al, ${ }^{21}$ who concluded that sustained maximum inspiratory pressure is more sensitive to detect differences in the endurance of those who undergo inspiratory muscle training. That is because the time limit is highly variable among subjects, and it can be influenced by many external factors, such as motivation, tolerance of unpleasant sensations, and the very strength and endurance of inspiratory muscles.

Additionally, there were significant increases in the inspiratory muscle training group compared with the calisthenics-and-breathing exercises group in abdominal excursion measurements and reductions of MMRC and dyspnea on exertion. Such reductions, when of 1 point or more, are considered clinically important differences. ${ }^{8}$ 


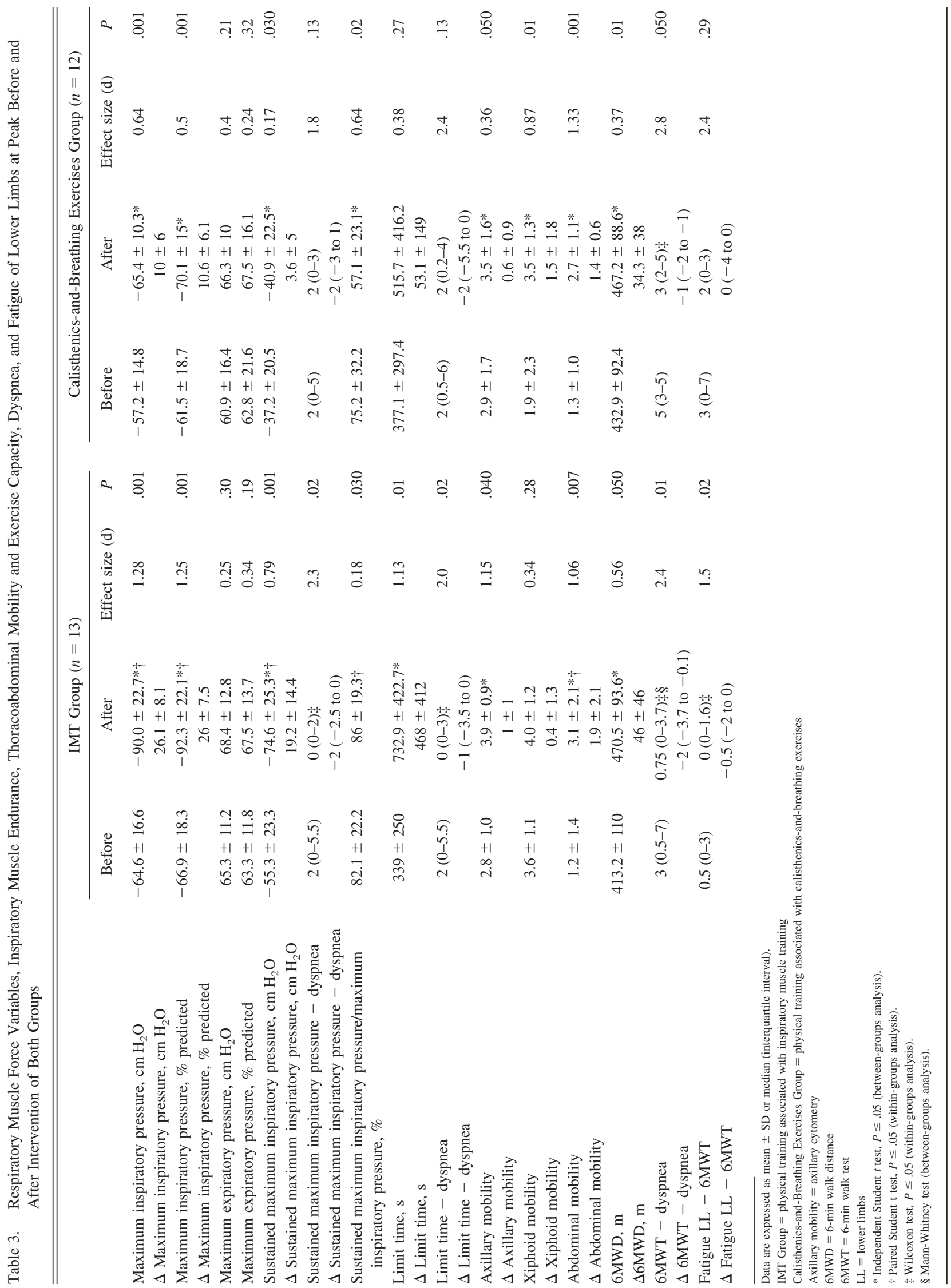


Table 4. Improvement After the Intervention of the Variables Inspiratory Muscle Strength and Endurance, Exercise Capacity, and Dyspnea in Subjects With and Without Respiratory Muscle Weakness in Each Group

\begin{tabular}{|c|c|c|c|c|c|c|c|c|}
\hline & \multicolumn{4}{|c|}{ IMT Group $(n=13)$} & \multicolumn{4}{|c|}{$\begin{array}{l}\text { Calisthenics-and-Breathing Exercises } \\
\text { Group }(n=12)\end{array}$} \\
\hline & $\begin{array}{c}\text { Maximum Inspiratory } \\
\text { Pressure } \leq 60 \mathrm{~cm} \\
\mathrm{H}_{2} \mathrm{O}(n=6)\end{array}$ & $\begin{array}{c}\text { Maximum Inspiratory } \\
\text { Pressure }>60 \mathrm{~cm} \\
\mathrm{H}_{2} \mathrm{O}(n=7)\end{array}$ & $\begin{array}{l}\text { Effect } \\
\text { Size } \\
\text { (d) }\end{array}$ & $P$ & $\begin{array}{c}\text { Maximum Inspiratory } \\
\text { Pressure } \leq 60 \mathrm{~cm} \\
\mathrm{H}_{2} \mathrm{O}(n=6)\end{array}$ & $\begin{array}{c}\text { Maximum Inspiratory } \\
\text { Pressure }>60 \mathrm{~cm} \\
\mathrm{H}_{2} \mathrm{O}(n=6)\end{array}$ & $\begin{array}{l}\text { Effect } \\
\text { Size } \\
\text { (d) }\end{array}$ & $P$ \\
\hline $\begin{array}{l}\Delta \text { Maximum inspiratory } \\
\text { pressure, } \mathrm{cm} \mathrm{H}_{2} \mathrm{O}\end{array}$ & $26.6 \pm 5.7^{* \dagger}$ & $21.4 \pm 6.9 \dagger$ & 0.81 & .02 & $12.5 \pm 5$ & $10 \pm 0$ & 0.71 & .19 \\
\hline $\begin{array}{l}\Delta \text { Sustained maximum } \\
\text { inspiratory pressure, } \mathrm{cm} \mathrm{H}_{2} \mathrm{O}\end{array}$ & $40 \pm 10 * \dagger$ & $17.1 \pm 4.8 \dagger$ & 3.0 & .001 & $0 \pm 0$ & $10 \pm 0$ & 0 & .55 \\
\hline$\Delta$ Limit time, $\mathrm{s}$ & $853.3 \pm 714.5$ & $420.5 \pm 133.1$ & 0.88 & .59 & $-56.6 \pm 201.7$ & $-180 \pm 0$ & 0.86 & .95 \\
\hline$\Delta 6 \mathrm{MWD}, \mathrm{m}$ & $44 \pm 18$ & $39.7 \pm 53.7$ & 0.21 & .99 & $60.5 \pm 52.11$ & $27 \pm 19.6$ & 0.85 & .96 \\
\hline$\Delta$ MMRC score & $-0.3 \pm 0.5 \dagger$ & $-1 \pm 0^{* \dagger} \dagger$ & 2.0 & .040 & $-0.5 \pm 1$ & $-0.5 \pm 0.5$ & 0 & .96 \\
\hline
\end{tabular}

Data are expressed as mean $\pm \mathrm{SD}$

IMT Group $=$ physical training associated with inspiratory muscle training

Calisthenics-and-Breathing Exercises Group = physical training associated with calisthenics-and-breathing exercises

$6 \mathrm{MWD}=6$-min walk distance

MMRC $=$ Modified Medical Research Council dyspnea scal

* 2-way analysis of variance, $P \leq .05$ (between-groups analysis, $\leq 60 \mathrm{~cm} \mathrm{H}_{2} \mathrm{O}$ vs $>60 \mathrm{~cm} \mathrm{H}_{2} \mathrm{O}$ ).

$\dagger 2$-way analysis of variance, $P \leq .05$ (between-groups analysis, inspiratory muscle training vs calisthenics-and-breathing exercises).

Such results are consistent with previous studies, which showed that inspiratory muscle training increases abdominal mobility ${ }^{10}$ and significantly decreases dyspnea, ${ }^{30,31,34}$ which is paramount in patients with COPD in pulmonary rehabilitation programs.

According to the American Thoracic Society/European Respiratory Society statement ${ }^{13}$ about pulmonary rehabilitation in patients with COPD, inspiratory muscle training is associated with general physical training would not bring additional benefits for dyspnea, and patients with respiratory muscle weakness could benefit more. However, our results, as mentioned above, do not show that. The subjects without respiratory muscle weakness who underwent inspiratory muscle training were those who had a greater reduction in dyspnea.

In the calisthenics-and-breathing exercises group, postintervention responses were not as expressive as in the inspiratory muscle training group; however, we saw gains in strength and endurance of the inspiratory muscles and thoracoabdominal mobility and reduction of at least 1 point in dyspnea, considered clinically important. It was also noted that there was a greater gain of inspiratory muscle strength than endurance, resulting in decreased post-intervention sustained maximum inspiratory pressure/maximum inspiratory pressure.

In previous studies, ${ }^{9,11}$ in which only calisthenics-andbreathing exercises had been proposed as an intervention, similarly to our results, increased thoracic mobility was noted, which was attributed to the reduction of dyspnea. Those authors believe that there is a change in feedback sensory and proprioceptive receptors of the rib cage, which reduces the central nervous efferent command for a given level of ventilation, providing desensitization to dyspnea.
The effects of calisthenics-and-breathing exercises are dependent on the type of exercise applied. Minoguchi et al, ${ }^{10}$ when implementing calisthenics-and-breathing exercises based on stretching exercises, unlike in our study, did not notice an increase in maximum inspiratory pressure. Because there is evidence in the literature that, in general, physical training does not improve the strength and endurance of the inspiratory muscles, ${ }^{31,34}$ it is likely that the increased maximum inspiratory pressure of subjects with COPD in this study has occurred due to the proposed exercises.

Regarding the capacity to exercise, it was found that the 6-min walk distance was not different between groups. Both groups had clinically important gains, greater than the minimum difference of $+25 \mathrm{~m}$ proposed in the literature ${ }^{35}$; in the inspiratory muscle training group, the increase was an average of $46 \mathrm{~m}$, and in the calisthenicsand-breathing exercises group, it was $34 \mathrm{~m}$. In the study by Reis et al, ${ }^{36}$ an increase in 6-min walk distance of almost $101 \mathrm{~m}$ was seen after 6 months of inspiratory muscle training associated with physical training in subjects with COPD. There are also studies that show that by adding inspiratory muscle training to general physical training, an increase in submaximal exercise capacity can be achieved, with clinically important improvement in relation to general physical training. ${ }^{32,34}$ In our study, there was no difference between those subjects with and without respiratory muscle weakness for both interventions.

In the inspiratory muscle training group, we observed a decrease in fatigue of the lower limbs on exertion. In conditions of overload of the inspiratory muscles, there is a reflex response to peripheral vasoconstriction directing blood flow to the respiratory muscles, causing fatigue of 


\section{Respiratory Muscle Training in COPD SubJects}

the lower limbs. However, studies show that inspiratory muscle training can attenuate such a response and improve the redistribution of blood flow, reducing fatigue. ${ }^{37}$ Nonetheless, further studies will be important to strengthen those findings.

Methodological limitations to be considered are the lack of a third group performing only general physical training. Also, an analysis of dynamic hyperinflation and at rest conditions will be needed to better explain the gains in strength and endurance of inspiratory muscles.

The results obtained in this study will be relevant in providing benefits to clinical practice, since we utilized 2 specific types of intervention that do not require expenditure, are easy to perform, and can be adapted for home care. More studies differentiating subjects with and without respiratory muscle weakness will be needed to better study the effects of such interventions.

\section{Conclusions}

We conclude that both programs of physiotherapy intervention developed in this study provided clinically meaningful benefits; they increased thoracoabdominal mobility and physical exercise capacity and decreased dyspnea on exertion. The main difference between the programs was that inspiratory muscle training, due to the specificity of training, was able to provide greater gains in inspiratory muscle endurance and strength and to decrease dyspnea in a clinically relevant manner. In addition, subjects with respiratory muscle weakness who underwent inspiratory muscle training had gains in strength and endurance of the respiratory muscles but not in dyspnea and exercise submaximal capacity.

\section{ACKNOWLEDGMENTS}

We thank all of the participants who agreed to be evaluated so that this study could be performed.

\section{REFERENCES}

1. Global Initiative for Chronic Obstructive Lung Disease (GOLD) Global Strategy for Diagnosis, management, and prevention of Chronic Obstructive Pulmonary Disease. 2011. http://www.goldcopd. org/guidelines-global-strategy-for-diagnosis-management.html. Accessed December 6, 2012.

2. Orozco-Levi M. Structure and function of the respiratory muscles in patients with COPD: impairment or adaptation? Eur Respir J Suppl 2003;46:41s-51s.

3. Bernard S, LeBlanc P, Whittom F, Carrier G, Jobin J, Belleau R, Maltais F. Peripheral muscle weakness in patients with chronic obstructive pulmonary disease. Am J Respir Crit Care Med 1998;158(2): 629-634.

4. Singer J, Yelin EH, Katz PP, Sanchez G, Iribarren C, Eisner MD, Blanc PD. Respiratory and skeletal muscle strength in COPD: impact on exercise capacity and lower extremity function. J Cardiopulm Rehabil Prev 2011;31(2):111-119.
5. Martín-Valero R, Rodríguez-Martínez MC, Cantero-Tellez R, Villanueva-Calvero E, Fernandez-Martín F. Advances in comprehensive pulmonary rehabilitation for COPD patients. In: Panos R, editor. COPD: clinical perspectives. Rijeka, Croatia: InTech; 2014:179-197.

6. Hill K, Jenkins SC, Hillman DR, Eastwood PR. Dyspnoea in COPD: can respiratory muscle training help? Aust J Physiother 2004;50(3): 169-180.

7. Ottenheijm CAC, Heunks LMA, Dekhuijzen PNR. Diaphragm muscle fiber dysfunction in chronic obstructive pulmonary disease. Am J Respir Crit Care Med 2007;175(12):1233-1240.

8. Gosselink R, De Vos J, van den Heuvel SP, Segers J, Decramer M, Kwakkel G. Impact of inspiratory muscle training in patients with COPD: what is the evidence? Eur Respir J 2011;37(2):416-425.

9. Kakizaki FPT, Shibuya MD, Yamazaki T, Yamada M, Suzuhi H, Homma I. Preliminary report on the effects of respiratory muscle stretch gymnastics on chest wall mobility in patients with chronic obstructive pulmonary disease. Respir Care 1999;44(4):409-414.

10. Minoguchi H, Shibuya M, Miyagawa T, Kokubu F, Yamada M, Tanaka H, et al. Cross-over comparison between respiratory muscle stretch gymnasticas and inspiratory muscle training. Intern Med 2002; 41(10):805-812.

11. Probst VS, Kovelis D, Hernandes NA, Camillo CA, Cavalheri V, Pitta F. Effects of two exercise training programs on Physical Activity in Daily Life in Patients with COPD. Respir Care 2011;56(11): 1799-1807.

12. Putt MT, Watson M, Seale H, Paratz JD. Muscle stretching technique increases vital capacity and range of motion in patients with chronic obstructive pulmonary disease. Arch Phys Med Rehabil 2008; 89(6):1103-1107.

13. Spruit MA, Singh SJ, Garvey C, ZuWallack R, Nici L, Rochester C, et al. An official American Thoracic Society/European Respiratory Society Statement: key concepts and advances in Pulmonary Rehabilitation. Am J Respir Crit Care Med 2013;188(8):e13-e64.

14. Randomization Plan. http://www.randomization.com. Accessed January 28, 2012.

15. Miller MR, Hankinson J, Brusasco V, Burgos F, Casaburi R, Coates A, et al. Standardisation of spirometry. Eur Respir J 2005;26(2):319_ 338.

16. Pereira CAC, Sato T, Rodrigues SC. Novos valores de referência para espirometria forçada em brasileiros adultos de raça branca. J Bras Pneumol 2007;33(4):397-406.

17. Black LF, Hyatt RE. Maximal respiratory pressures: normal values and relationship to age and sex. Am Rev Respir Dis 1969;99(5):696702 .

18. Neder JA, Andreoni S, Lerario MC, Nery LE. Reference values for lung function tests. II. Maximal respiratory pressures and voluntary ventilation. Braz J Med Biol Res 1999;32(6):719-727.

19. Ramirez-Sarmiento A, Orozco-Levi M, Guell R, Barreiro E, Herna$\operatorname{dez} \mathrm{N}$, Mota $\mathrm{S}$, et al. Inspiratory muscle training in patients with chronic obstructive pulmonary disease. Structural adaptation and physiologic outcomes. Am J Respir Crit Care Med 2002;166(11): 1491-1497.

20. Larson JL, Covey MK, Berry J, Wirtz S, Alex CG, Matsuo M. Discontinuous incremental threshold loading test. Chest 1999;115(1): 60-67.

21. Hill K, Jenkins SC, Philippe DL, Shepherd KL, Hillman DR, Eastwood PR. Comparison of incremental and constant load tests of inspiratory muscle endurance in COPD. Eur Respir J 2007;30(3): 479-486.

22. Dias FD, Sampaio LMM, da Silva GA, Gomes ÉLFD, do Nascimento ESP, Alves VLS, et al. Home-based pulmonary rehabilitation in patients with chronic obstructive pulmonary disease: a randomized clinical trial. Int J Chron Obstruct Pulmon Dis 2013;8:537-544. 


\section{Respiratory Muscle Training in COPD SubJects}

23. Borghi-Silva A, Mendes RG, Silva ES, Paulucci HL, Picchi PC, Di Lorenzo VAP. Medida da amplitude tóraco-abdominal como método de avaliação dos movimentos do tórax e abdome em indivíduos jovens saudáveis. Fisioter Bras 2006;7(1):25-29. Article in Portuguese.

24. ATS Committee on Proficiency Standards for Clinical Pulmonary Function Laboratories. ATS statement: guidelines for the six-minute walk test. Am J Respir Crit Care Med 2002;166(1):111-117.

25. American Thoracic Society, American College of Chest Physicians. ATS/ACCP statement on cardiopulmonary exercise testing. Am J Respir Crit Care Med 2003;167(2):211-277.

26. Bruce RA, Kusumi F, Hosmer D. Maximal oxygen intake and nomographic assessment of functional aerobic impairment in cardiovascular disease. Am Heart J 1973;85(4):546-562.

27. Kovelis D, Segretti NO, Probst VS, Lareau SC, Brunetto AF, Pitta F. Validação do Modified Pulmonary Function Status and Dyspnea Questionnaire e da escala do Medical Research Council para o uso em pacientes com doença pulmonar obstrutiva crônica no Brasil. J Bras Pneumol 2008;34(12):1008-1018. Article in Portuguese.

28. Dourado VZ, Tanni SE, Antunes LCO, Paiva SAR, Campana AO, Renno ACM, Godoy I. Effect of three exercise programs on patients with chronic obstructive pulmonary disease. Braz J Med Biol Res 2009;42(3):263-271.

29. Langer D, Probst VS, Pitta F, Burtin C, Hendriks E, Schans CPVD, et al. Guia para prática clínica: fisioterapia em pacientes com Doença Pulmonar Obstrutiva Crônica (COPD). Rev Bras Fisioter 2009;13(3): 183-204. Article in Portuguese.
30. Magadle R, McConnell AK, Beckerman M, Weiner P. Inspiratory muscle training in pulmonary rehabilitation program in COPD patients. Respir Med 2007;101(7):1500-1505.

31. Weiner P, Azgad Y, Ganam R. Inspiratory muscle training combined with general exercise reconditioning in patients with COPD. Chest 1992;102(5):1351-1356.

32. Beckerman M, Magadle R, Weiner M, Weiner P. The effects of 1 year of specific inspiratory muscle training in patients with COPD. Chest 2005;128(5):3177-3182.

33. Cohen J. Statistical power analysis for the behavioral sciences. 2nd edition, Hillsdale, NJ: Lawrence Erlbaum Associates; p. 567, 1988.

34. Wanke T, Formanek D, Lahrmann H, Brath H, Wild M, Wagner C, Zwick, $\mathrm{H}$. Effects of combined inspiratory muscle and cycle ergometer training on exercise performance in patients with COPD. Eur Respir J. 1994;7(12):2205-2211.

35. Holland AE, Hill CJ, Rasekaba T, Lee A, Naughton MT, McDonald $\mathrm{CF}$. Updating the minimal important difference for six-minute walk distance in patients with chronic obstructive pulmonary disease 2 . Arch Phys Med Rehabil 2010;91(2):221-225.

36. Reis LFF, Guimarães FS, Fernandes SJ, Cantanhede LA, Dias CM, Lopes AJ, De Menezes SLS. A long-term pulmonary rehabilitation program progressively improves exercise tolerance, quality of life and cardiovascular risk factors in patients with COPD. Eur J Phys Rehabil Med 2013;49(4):491-497.

37. Ribeiro JP, Chiappa GR, Callegaro CC. Contribuição da musculatura inspiratória na limitação ao exercício na insuficiência cardíaca: mecanismos fisiopatológicos. Rev Bras Fisioter 2012;16(4):261-267. Article in Portuguese. 